\title{
Editorial
}

\section{Financial services marketing research: Retrospect and prospect}

Journal of Financial Services Marketing (2015) 20, 231-233. doi:10.1057/fsm.2015.22

Throughout 2015 the Journal of Financial Services Marketing has been celebrating its 20 th

Anniversary year. To mark this anniversary, this final issue of Volume 20 has been designated the 20th Anniversary Special Issue. The theme of the Special Issue is reflecting on the past and looking to the future.

Much has changed in the global landscape of financial services over the last 20 years, including changes to regulation, technological innovation and, not least, a major financial crisis, to name but a few key impacts. These changes have had a profound effect on the structure of the industry and the nature of competition within it and the ways in which financial services providers and customers interact with one another. Consequently, it has been suggested that: 'The field of financial services marketing is in need of new perspectives and paradigms that can explain the financial behavior of consumers and markets today. This need has grown over the past decade and has become more pronounced since the global financial crisis' (Harrison and Estelami, 2014).

Set against this context, the papers in this Special Issue consider various trends and developments in financial services marketing research. They reflect on the body of knowledge that has been built up over this time, and outline agendas for future research to take financial services marketing research into the next 20 years.

In the first paper, Trust in Financial Services: Retrospect and Prospect by James F. Devlin, Christine T. Ennew, Harjit S. Sekhon and
Sanjit K. Roy, the authors reflect on the body of research on trust in financial services and consider the prospects for trust into the future. The authors argue that fostering and maintaining high levels of trust in the financial services sector is crucial due to the specific nature of many financial services. Following a discussion of trust concepts, the paper reports on evidence from a substantial body of work undertaken over the last 10 years by the Centre for Risk, Banking and Financial Services. The Centre has amassed a large amount of longitudinal data which provide important insights into the nature of trust, consumer perceptions of trust, trends in levels of trust both within the financial services sector and in comparison with other sectors.

Overall, the findings reveal that, contrary to popular belief, the financial services sector as a whole is trusted more than some comparator institutions, and that aggregate levels of trust in the sector have remained relatively stable over time, showing only minor fluctuations following the financial crisis. Most noteworthy though are the important differences between provider types, and these differences have become more profound in the recent past. The data reveals that the most trusted type of provider is clearly the broker/advisor, whereas banks are the least trusted. Over time, trust in brokers/advisors has remained relatively stable. However, trust in banks has declined in recent years, compared with rising levels of trust in credit card providers. The authors provide suggestions as to how trust in the sector may be improved and provide an analysis of current 
initiatives to improve trust levels in the sector in general and in banking in particular.

Still on the theme of trust, the second paper, Cognitive Catalysts for Distrust in Financial Services Markets: An Integrative Review by Hooman Estelami, offers a partial explanation for the trust picture set out in the previous paper. Estelami argues that whilst some of the depletion of public trust in financial institutions can be linked to the misbehaviour of individual financial services providers, consumers themselves often serve as a catalyst for trust dilution. For example, Estelami suggests that much of the distrust can be attributed to a general lack of consumer understanding of financial matters, undisciplined actions of consumers and poor preparedness in engaging in financial decisions that carry significant consequences. He suggests that there are abundant opportunities for exploring the 'catalysts for trust depletion' attributable to consumers' cognitive limitations and this may call for a paradigm shift in our understanding of the ownership of relational trust in financial services exchanges.

The paper thus provides a comprehensive review of four cognitive phenomena that inhibit consumers' information processing abilities and contribute to the depletion of trust in financial services: Poor estimation of risks; laze in information search; poor appreciation for the time value of money; effects of shortterm memory limitations. On the basis of a comprehensive integrative review, the paper discusses what research has taught us and highlights gaps in our understanding. The paper also provides key pointers for where further research, industry action and government intervention could contribute to equipping consumers with the means to overcome these cognitive limitations in order to improve their financial decision quality.

Over the 20 year history of the Journal, few developments have had such a dramatic widescale impact on the operation of financial institutions or the behaviour of customers as innovations in technology. In particular, the adoption and use of banking innovation is a continuing issue for financial services marketing researchers. Despite a substantial volume of empirical research over the last decade or more, the challenge of influencing innovation adoption persists. Moreover, as digital channels continue to evolve there is a need to integrate and re-evaluate extant streams of evidence to identify where avenues of enquiry are exhausted and where there are areas that warrant attention. Set against this context, in the third paper, Online Banking Adoption: We Should Know Better 20 Years On, Kathryn Waite and Tina Harrison reflect on the accumulated knowledge of online banking adoption research over the history of the Journal and consider what we have learnt and where research can be usefully directed moving forward.

On the basis of an audit of published research over a 10-year period that captures the rise and maturity of research in this area, the authors identify the core theories and approaches that have been used to study online banking adoption. The study finds a widespread application of the Technology Adoption Model (TAM), including variations and extensions to the core model. The paper provides an informed critique of the over-reliance on TAM and TAM plus models drawing on current debate within the Information Systems (IS) domain. The authors question the relevance of the ongoing application of TAM to banking innovation adoption studies and also cast doubt on the contribution of the application of TAM in many previous studies. The paper concludes with a call for research to formulate, operationalise and test fresh theory and suggests that there is scope to introduce and examine adoption drivers using alternative lenses including, but not limited to: task-technology fit theory, engagement theory, empowerment theory, liminality theory, domestication theory, addiction theory, hedonic theory, identity signalling theory and resistance theory.

Continuing with the theme of technology, the fourth paper, Technology and Financial Services: Marketing in Times of U-Commerce by Stacey Morrison, Leyland Pitt and Jan Kietzmann, takes a more forward-looking 
approach to formulating digital marketing objectives and strategy for financial services. It uses the U-Commerce framework to challenge financial services marketing decision makers to consider reformulating marketing objectives in an age of ubiquitous technological networks. The paper outlines the four U's of U-Commerce: ubiquity, universality, uniqueness and unison. Using the dichotomies of uniqueness and ubiquity on one hand, and ultra-conscious and unconscious on the other, the authors create a $2 \times 2$ framework that financial services marketing scholars can use to explore and position research, and for practitioners to guide strategic direction. The framework gives rise to four broad marketing objectives that financial services marketers can strive for: amplification, attenuation, contextualization and transcension. The authors identify and discuss four broad marketing strategies that map on to the objectives, including: nexus marketing, sync marketing, immersion marketing and transcension marketing. The strategies revolve around attenuating or amplifying marketing communication, and either enhancing timeplace specificity or overcoming it.

The authors contend that in the age of U-Commerce a useful question to guide a financial services marketer's technology application is whether the consumer can do something 'useful' with the technologies utilized by financial services firms. Using the U-Commerce framework, financial services marketers can not only understand the technologies that become part of ubiquitous networks, but can also specify specific marketing objectives and can then formulate appropriate marketing strategies to achieve these objectives.

The final paper in this Special Issue, General Insurance Marketing: A Review and Future Research Agenda by Julie Robson, highlights the lack of attention that the Journal has paid to the general insurance industry and calls for research to address this important area. The paper reminds us that in talking about financial services we are addressing a diverse industry comprising many different forms of organisations and product offerings, and that focusing our research efforts narrowly on banking services potentially limits both the application and development of theory that may be of wider relevance. Not only that, the insurance industry represents a sizeable proportion of the global financial services industry. Thus, theoretically relevant research potentially can have wideranging practical impact.

Robson argues that insurance is both theoretically and practically different, giving rise to different interactions between providers and consumers (both individuals and organisations) that are worthy of study. For example, insurance is essentially a risk transfer mechanism and comprises one of the more intangible financial services offerings. Insurance is often misunderstood by consumers; some believe it is an investment which in turn affects their behaviour towards the product. For some types of insurance there is a legal obligation to have it (that is, car insurance), or at least a strong link to other types of products (that is, buildings insurance linked to a mortgage). Most general insurance is renewed on an annual basis. All of these affect the consumer search and decisionmaking process and ongoing interactions with providers thereafter, yet there has been virtually no research that has focused on, for example, consumer decision-making processes in nonvoluntary situations. Based on a review of research published to-date on general insurance in the Journal, Robson assesses where research attention has been focused and identifies where there is an urgent need for future research. In setting out a future research agenda for research on the general insurance industry, the paper outlines five key themes: trust, transparency and simplification, technology, High Net Worth Individuals, and Takaful (Islamic insurance). The paper outlines key areas and research questions that future research can usefully explore in each of these themes and serves to provide a firm foundation for future researchers to build on.

Tina Harrison Editor-in-Chief E-mail: Tina.Harrison@ed.ac.uk 